\title{
A simple modification in technique preserves oblique muscle fibers during peroral endoscopic myotomy
}

A 15-year old boy was diagnosed with type II achalasia cardia at our hospital and peroral endoscopic myotomy (POEM) was performed by the posterior route (5 o'clock). The standard steps of the POEM procedure included: mucosal incision, submucosal tunneling, myotomy, and closure of the incision with endoclips [1]. We incorporated an important modification in our myotomy technique in order to preserve the oblique muscle fibers close to the gastroesophageal junction.

In this technique, we identified two penetrating vessels at the gastric end of submucosal tunnel ( $\mathbf{F i g . 1} \mathbf{a}, \mathbf{b}$ ). These vessels have been described as a marker of the junction between the circular and oblique muscle fibers [2]. The second penetrating vessel was not coagulated and served as a guide for later identification of the oblique muscle fibers. Myotomy was performed in the usual fashion until the gastroesophageal junction was reached. Subsequently, the direction of the myotomy was re-adjusted in such a fashion that it was possible to selectively avoid severing the oblique muscle fibers (๖ Fig.1 c). A lax gastroesophageal junction could be appreciated after the POEM procedure ( $\mathbf{F i g . 2}$ ). Finally, the mucosal incision was closed with the standard technique using multiple endoclips ( V Video 1).

POEM has emerged as a safe and efficacious treatment modality for achalasia cardia, with encouraging results in the pediatric population as well [3]; however, gastroesophageal reflux disease (GERD) is a major concern after POEM [4]. The oblique fibers form an important component of the anti-reflux barrier and are usually severed during posterior POEM. In this video, we demonstrate a novel technique for POEM in which the oblique fibers are preserved to prevent GERD.

\section{Competing interests}

None

The authors

Zaheer Nabi ${ }^{1}$, Mohan Ramchandani ${ }^{1}$, Rama Kotla², Radhika Chavan' ${ }^{1}$, Santosh Darisetty ${ }^{2}$, D. Nageshwar Reddy ${ }^{1}$

1 Department of Gastroenterology, Asian Institute of Gastroenterology, Hyderabad, India

2 Department of Anesthesia, Asian Institute of Gastroenterology, Hyderabad, India

\section{Corresponding author}

\section{Zaheer Nabi, MD}

6-3-661, Asian Institute of Gastroenterology, Hyderabad-500082, India zaheernabi1978@gmail.com

\section{Endoscopy_UCTN_Code_TTT_1AO_2AN}
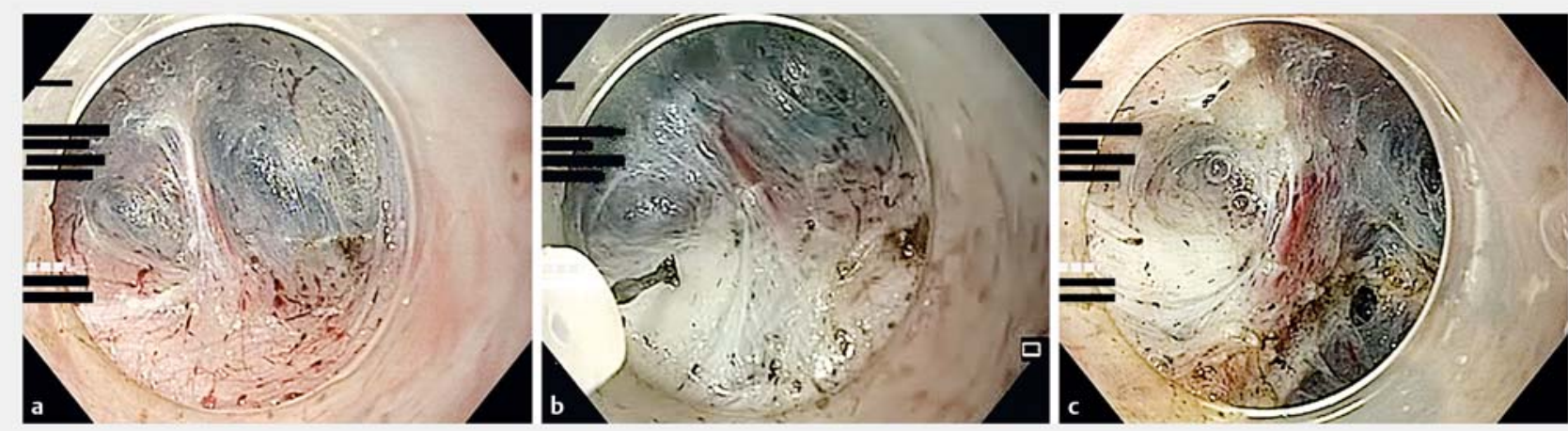

- Fig. 1 Endoscopic views during peroral endoscopic myotomy showing: a the first penetrating vessel, which was revealed during submucosal tunneling towards the gastric side; $\mathbf{b}$ the second penetrating vessel marking the junction between the oblique (left) and circular muscle fibers (right), with the knife pointing towards the oblique muscle fibers; c endoscopic myotomy being performed towards the right of the second penetrating vessel, thereby preserving the oblique muscle fibers. 


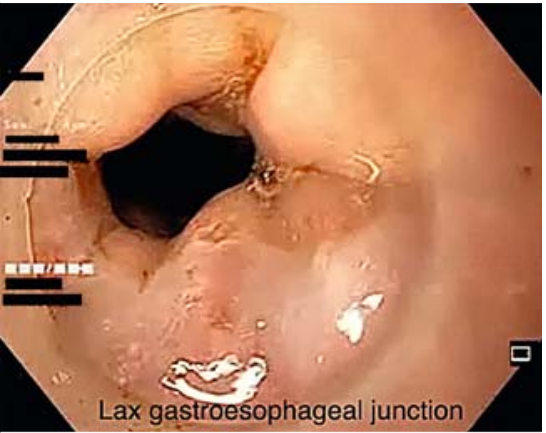

- Fig. 2 Endoscopic appearance after completion of the myotomy showing the lax gastroesophageal junction.

\section{References}

[1] Nabi Z, Ramchandani M, Reddy DN. Per-oral endoscopic myotomy in a child with achalasia cardia. J Pediatr Gastroenterol Nutr 2017; 65: e44

[2] Tanaka S, Kawara F, Toyonaga T et al. Two penetrating vessels as a novel indicator of the appropriate distal end of peroral endoscopic myotomy. Dig Endosc 2018; 30: 206-211

[3] Lee Y, Brar K, Doumouras AG et al. Peroral endoscopic myotomy (POEM) for the treatment of pediatric achalasia: a systematic review and meta-analysis. Surgical endoscopy 2019; $33: 1710-1720$

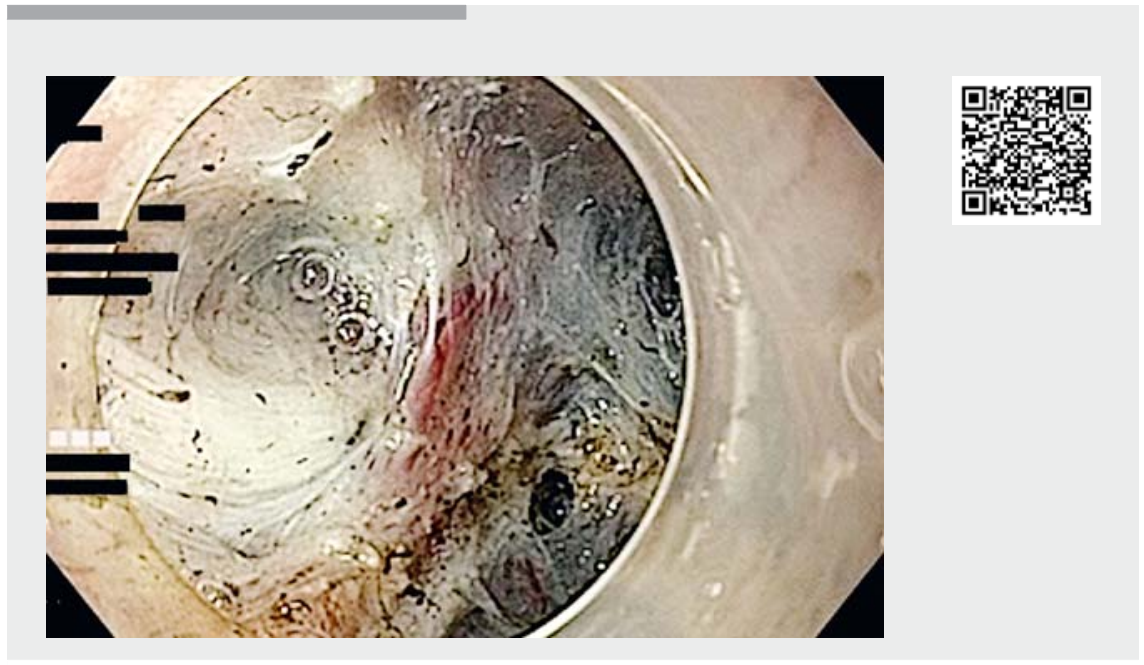

$\checkmark$ Video 1 Video demonstrating the technique to preserve the oblique muscle fibers during peroral endoscopic myotomy.

[4] Kumbhari V, Familiari P, Bjerregaard NC et al. Gastroesophageal reflux after peroral endoscopic myotomy: a multicenter case-control study. Endoscopy 2017; 49: 634-642

\section{Bibliography}

DOI https://doi.org/10.1055/a-0986-3112

Published online: 21.8.2019

Endoscopy 2020; 52: E37-E38

(c) Georg Thieme Verlag KG

Stuttgart $\cdot$ New York

ISSN 0013-726X

\section{ENDOSCOPY E-VIDEOS \\ https://eref.thieme.de/e-videos}

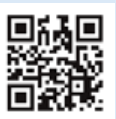

Endoscopy E-Videos is a free access online section, reporting on interesting cases and new techniques in gastroenterological endoscopy. All papers include a high quality video and all contributions are freely accessible online.

This section has its own submission website at https://mc.manuscriptcentral.com/e-videos 